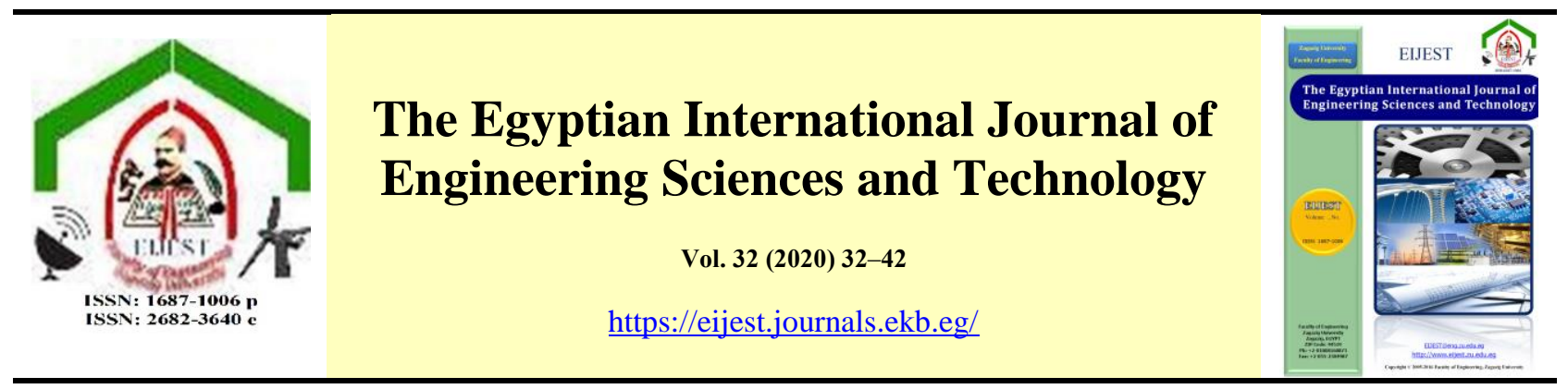

\title{
Various classifications for architectural form finding process
}

\begin{tabular}{|c|c|}
\hline \multicolumn{2}{|c|}{$\begin{array}{l}\text { Hussein M. Elshanwany }{ }^{\mathrm{a}} \text {, Zeyad El-sayad }{ }^{\mathrm{b}} \text {, Hadeer S. Nasser }{ }^{\mathrm{c} *} \\
{ }^{a} \text { Professor of architecture and building technology, Faculty of engineering, Zagazig university, Egypt } \\
{ }^{b} \text { Assistant Professor, Faculty of engineering, Alexandria university, Egypt } \\
{ }^{c} \text { Demonstrator at Architectural engineering dep., Faculty of engineering, Zagazig university, Egypt }\end{array}$} \\
\hline ART I CLE INFO & A B S T RACT \\
\hline $\begin{array}{l}\text { Keywords: } \\
\text { Form finding } \\
\text { Digital morphogenesis } \\
\text { Generative design } \\
\text { Performance-based design } \\
\text { Integrated design }\end{array}$ & $\begin{array}{l}\text { In the age of digital revolution, architects have to keep pace with latest advances } \\
\text { in technology and computing, which in turn affected architectural design and } \\
\text { fabrication. In architectural form finding process, some schools of thought } \\
\text { encourage personal inspiration, intuition of the architect and his sense of beauty, } \\
\text { while others depend on specific design approaches based on rules and fulfillment of } \\
\text { design requirements in generating architectural form. This paper presents a review } \\
\text { on various form finding philosophies that have been existed in architectural design } \\
\text { over the past century till now. In addition, a taxonomy for digitally generated forms } \\
\text { is presented herein into two categories. Through investigating these different } \\
\text { approaches of form finding process, some of them focus only on the qualitative and } \\
\text { aesthetic aspects of the architectural form and didn't take into consider building } \\
\text { performances such as functional, environmental, structural or acoustic, while } \\
\text { others focus on the performative aspects. Moreover, dealing with the current } \\
\text { complex geometries and advanced technologies made it important to depend on an } \\
\text { Integrated design: a Generative performative design Approach that achieves } \\
\text { balance and takes into consider both aesthetic aspects as well as the performative } \\
\text { considerations of the building such as functional, environmental, structural or } \\
\text { economic, in order to find the optimal solution at early stages of the form finding } \\
\text { process. }\end{array}$ \\
\hline
\end{tabular}

\section{Introduction}

Currently, the technological development has a great influence on the architectural practice and education. Then the role of the architects has been changed and they have to keep pace with latest advances and technologies, which enable them to discover unpredictable and creative solutions in the design process. In addition, dealing with complex geometries and meeting design requirements such as structural, functional, environmental, economic or social[1]. Architectural form finding process is considered one of the most important issues in the field of architectural education and practice. It can be defined as a design approach in which the generating forms based on a number of rules or algorithms derived from mathematical tools such as Processing, Rhino, Grasshopper and other scripting platforms. It also had been existed before the age of computation [2]. In generating form, many schools of thought encourage the personal inspiration of the architect and his sense of beauty, while others emphasize on the need for specific design approaches based on rules rather than the designer's intuition and avoiding self-indulgence and expressive language based on a specific style [3]. In addition to dealing with complex forms and the emergence of sustainability trends as a 
socio-economic phenomenon have affected all aspects of life and extended to architectural design and construction technology. Through investigating various approaches of form finding process, some of them focus only on the qualitative and aesthetic aspects of the architectural form[3, 4] and didn't take into consider building performances such as functional, environmental, structural or acoustic, while others focus on the performative aspects, which resulted in a un-optimal solution at one hand and an optimal solution at the other hand, which may not be acceptable from aesthetic point of view[5].

Moreover, the emergence of questions about the validity of the used design approach, the relationship between functional requirements and building form, aesthetic considerations and construction systems, the impact of the surrounding environment and structure, user needs and construction cost [1,5]. This research has combined methodologies, through literature review for comparative analytical approach; to investigate various form finding approaches and includes three main parts:

- First: a historical background about the philosophies of architectural form generation before the age of computation.

- Second: reviewing various classifications for digitally generated forms (digital morphogenesis).

- Third: comparative analysis of distinguishing features and potentials for each approach.

\section{Form Finding Process}

\subsection{Definition}

There is no single definition of the generative form finding process, as they vary according to the multiple views of architectural historians. It can be described as a design approach in which the generating forms based on a number of rules or algorithms derived from mathematical tools such as Processing, Rhino, Grasshopper and other scripting platforms[6].

\subsection{The roots of form finding process in architecture}

Many form finding techniques existed long before digital revolution, at the beginning of the $20^{\text {th }}$ century. Several architects, engineers and innovative designers such as Frei Otto and Frederick Kiesler, used design approaches very similar to the current trends based on computation. Therefore, it is not true to think that these methods are very recent and that it is impossible to use them without the aid of computer. In the late 1980s and early 1990s, before the development and spread of the use of computers, Peter Eisenmann developed many design techniques such as scaling, fractals, superposition and congruence influenced by Jacques Derrida's deconstructive theory. Eisenmann applied these techniques to the rules of order and he developed several projects such as Bio centrum in Frankfurt (1987) and Nunotani headquarters see Fig 1. in Tokyo (1992). Thus, Eisenmann's design approach is considered to be the first attempt at contemporary deductive design[7].

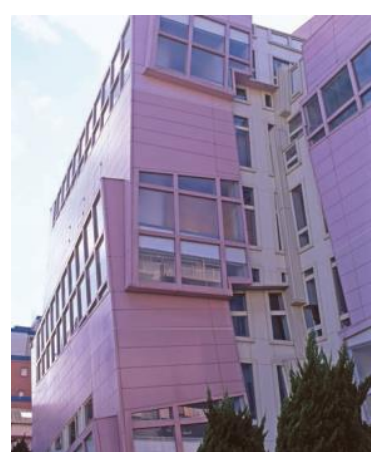

Fig. 1. Nunotani Headquarters in Tokyo (1992) [7].

\section{Classification of traditional form-finding philosophies}

\subsection{Design processes driven by nature}

At the end of the $19^{\text {th }}$ century, architects and thinkers began to call for universal design principles, replacing individual expression and the mere reimitation of historical styles. So, they directed towards nature and science. For example: the entrance to the Paris metro station see Fig 2. by Hector Guimard and Santiago Calatrava designs, such as: City of Arts and Sciences in Valencia (1998) see Fig 3. which It was not based only on imitating form and appearance but simulating the intelligent processes of living organisms[8].

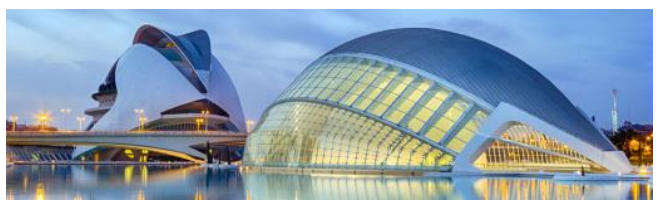

Fig. 2. City of Arts and Sciences in Valencia (1998) designed by Santiago Calatrava [8]. 


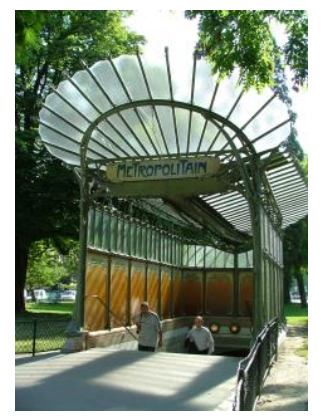

Fig. 3. Paris metro station entrance designed by Hector Guimard [8].

\subsection{Design processes driven by geometry}

Geometric rules and proportions are the main driver in the process of form finding for many significant architects, including Louis Sullivan, who used techniques such as quadrature and triangulation to design decorative patterns, while Frank Lloyd Wright employed geometric rules and proportions to design the Unity Temple in Chicago ( 1908), where his design based on a modular grid with dimensions of 2 meters that were refined and emphasized with dimensions derived from square and incompatible with the grid[9].

Later, Le Corbusier tried to develop design approache based on proportions in his book Modulor (1948), where he reached the golden ratio as the key to achieving beauty. He also applied his famous proportional scheme in two of his most important works: the Notre Dame du Haut Chapel see Fig 4. in Ronchamp (1954) and Phillips' Pavilion see Fig 5. in Brussels (1958), which prove that the rules of modular proportions is considered tools that providing unexpected designs[10].

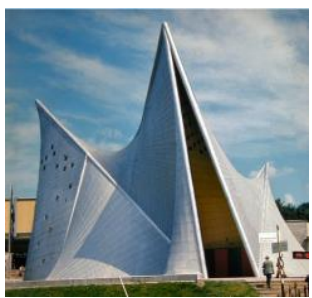

Fig. 4. Phillips' Pavilion in Brussels (1958) [10].

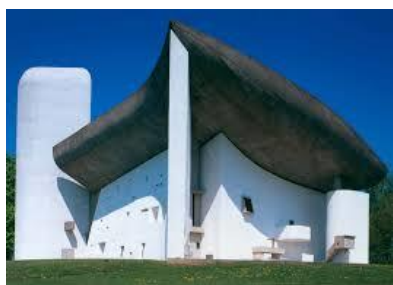

Fig. 5. The Notre Dame du Haut Chapel in Ronchamp (1954) [10].

\subsection{Design processes driven by context}

Other architects relied in their design approach on site response, effect of the surrounding environment

and the use of morphological and typological elements, forming the design movement known as postmodernism. One of the most prominent architects of this trend is "Aldo Rossi", who used the basic patterns common in historical sites in Italian cities, such as: octagonal, column-rows, arches, etc., in their explicit forms, regardless of function or scale. For example, the octagonal tower shape was used in the Teatro del Mondo project see Fig 6. in Venice (1979) [11].

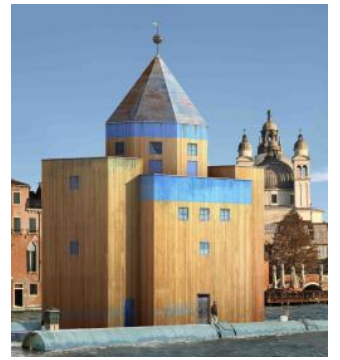

Fig. 6. Teatro del Mondo project in Venice (1979) [11].

\subsection{Design processes driven by performance}

Unlike the previous approaches, many architects and designers adopted an entirely different approach in form finding process, based on evaluating the building's structural performance, the properties of building materials and focused on the minimal possible form. While the building relationship with the surrounding environment played a secondary role in this direction. One of the most prominent pioneers of this trend is Shukhov Vladimir. One of his most important projects is a metal tower built for an industrial exhibition in Nizhny Novgorod (1896), which is the first metal construction from a hyperboloid diagrid structure see Fig 7. This structure has been duplicated in many Shukhov projects such as the communication tower see Fig 8. in Moscow, which represents an ideal combination between mathematical shape, optimized structure and material performance $[1,5]$.

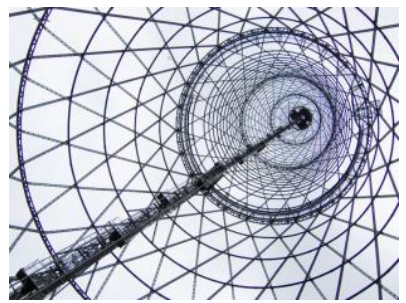

Fig. 5. Diagrid structure of

Shukhov Vladimir metal tower [4].

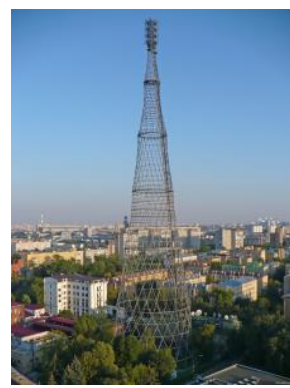

Fig. 4. Communication tower in Moscow [4]. 


\section{4. $2^{\text {nd }}$ classification for digitally generated forms (digital morphogenesis)}

The term morphogenesis is derived from the Greek language and consists of two parts: (morph) meaning formation (form) while (genesis) means birth, so it literally means the birth of form [4]. In digitally generated forms, the final outputs are not predictable and are characterized by harmony, continuous and dynamic transformations have replaced static types of traditional design processes. Also, the horizontal plan is no longer the generator of the design, but the vertical section of the building has an important analytical role. Various digitally based generative techniques has made radical shift from "form making" to "form finding" and in the domain of form, the stable is supplanted by the variable, peculiarity by assortment [2,9]. Thus, digital morphogenesis focuses on the adaptive properties and appearance, which is not done according to a specific horizontal plans, but is derived through a number of rules or algorithms of digital, physical and technological tools[1].

Michael Hensel defined it as: a self-organizing process that tracks the growth of organisms from which architects learn[12]. Rivka and Robert Oxman also defined it as the use of numerical generative methods to find materials for form and the evolution of their genesis. They also classified the form finding processes into six sections according to the main factor controlling the process as follows: mathematical, structural, building materials, environmentally, manufacturing or performance[7].

Architectural design has been affected by digital revolution, which resulted in increasing the use of information technology tools that enable designers to explore new architectural forms as well as dealing with complex geometries. They are no longer used as drafting and presentation tools, but they could generate infinite number of architectural solutions and transformations to meet specific design requirements and concepts. These new forms cannot be expressed by traditional old methods, but are computed through computational generative methods as these generative processes open new dimensions for ideas and creativity[1]. This paper tries to analyze potentials of morphogenesis with some of these subcategories; with giving examples as follows:

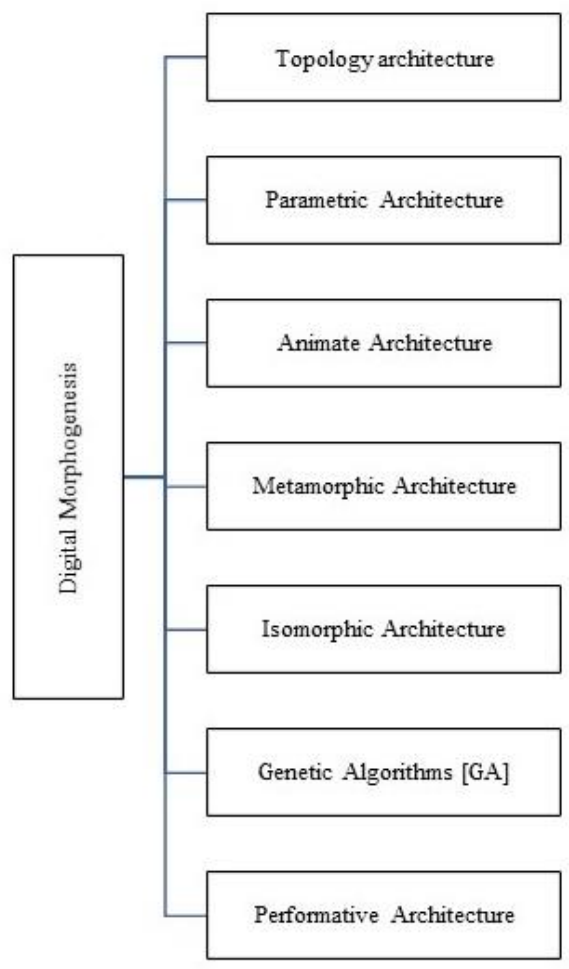

Fig. 6 Digital morphogenesis classification

\subsection{Topology architecture}

It is a design approach that has moved away from the deconstructive approach and its contradictions and conflict to develop a more flexible and communicative approach. This flow and connectivity arise through a design approach that differs from the Euclidean geometry of discrete volumes represented in the Cartesian coordinates of the space, by using a geometric shape made up of connected curves and surfaces known mathematically as "Non-Uniform Rational B-Splines" NURBS curves and surfaces are able to control by changing the location of the control points, the associated weights and the knots that form them. They also make incoherent configurations of topographic spaces, possible computationally $[1,10]$.

Mobius House see Fig 10. is an important example designed by the architect Van Berkel in Amsterdam, Netherlands and was built in 1998, the project idea was derived from one of the topological formations, which is the Mobius strip. The final form of the project differs from the initial form of the idea see Fig 11., it is a folded sheet see Fig 12. 
developed from Mobuis strip as they both have the same topographic characteristics[13].

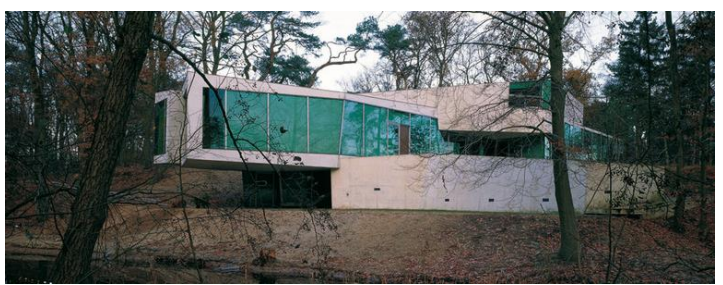

Fig. 10. Mobius House [13].

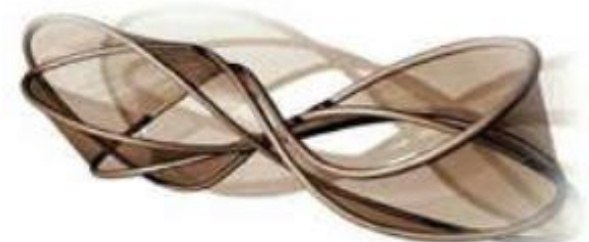

Fig. 11. The embodiment of the concept [13].

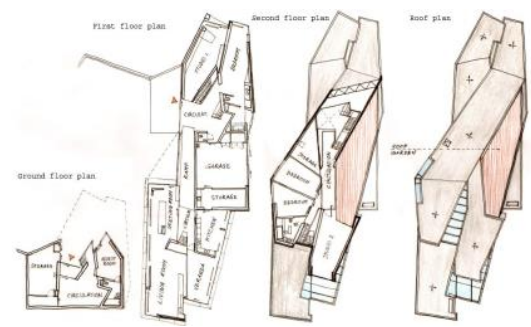

Fig. 12. Project floor plans [10].

\subsection{Parametric Architecture}

There are two parametric methodologies. The $1^{\text {st }}$ one considers all designs are parametric as they depend on parameters, as location, structural loads , solar radiation, cost and wind $[14,15]$. The other methodology thinks about parametric design as utilizing specific tools such as (Grasshopper, Maya MEL, Rhino Scripting platforms) to improve configuration by interconnecting and planning design elements $[14,16]$. Nasser $H$. designed a parametric shading element see Fig 13,14., the design concept was inspired by lines of magnetic field, by changing some values and parameters, it resulted in different and infinite number of design solutions see Fig 15.

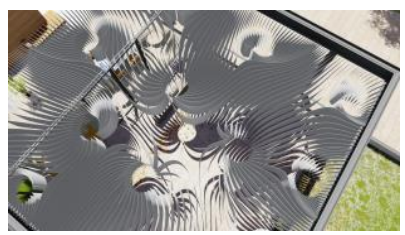

Fig. 13. Top view of the shading element

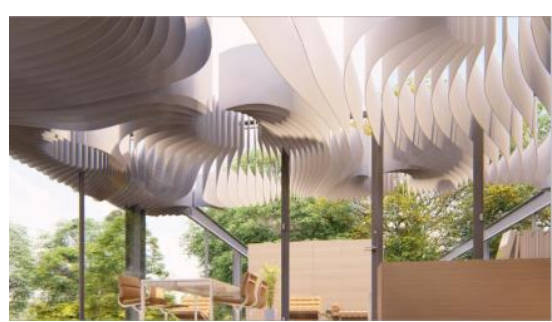

Fig. 14. Parametric design of shading element

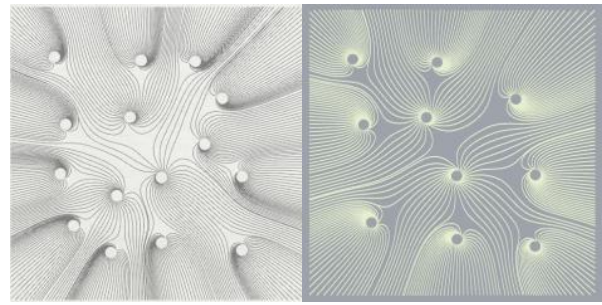

Fig. 15. Design alternatives resulted from changing parameters values

\subsection{Animate Architecture}

Greg Lynn is considered the first architect to use Animation Software, not only as a tool for rendering, but in the process of architectural form finding. It is defined by the co-presence of motion and force at the moment of formal conception. Force as an initial condition, changes the atmosphere, which effects both motion and particular inflections of form" $[1$, 13], see Fig 16,17.

Fig. 16. Space of traditional architecture free from forces [1].

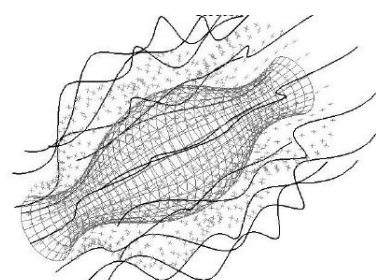

Fig. 17. Space in Animate architecture that affects form finding process [1]. 


\subsection{Metamorphic Architecture}

This approach is based on creating a simplified form and then making appropriate transformations such as bending, twisting, lattice box or morphing, etc, by changing the form, which is chosen according to the design concept. By adding a fourth dimension, the time dimension to the transformation processes, animation software provides the ability to express the building and surrounding space and then choose the best frames during the animation [12].

For example, an office building designed by Gehry Ostra in Hannover, Germany, is in the form of a prism curving towards a nearby park see Fig 18 . [13].

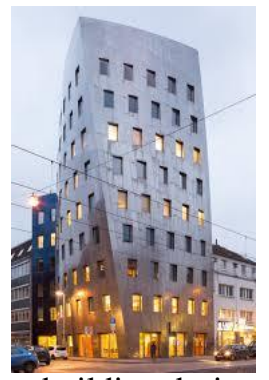

Fig. 18. office building designed by Gehry

\subsection{Isomorphic Architecture}

Geometrical forms in isomorphic architecture are monolithic models with forces of attraction and internal mass. Based on isomorphic polysurface or what is called "meta clay", "meta-ball" or "blob models". The blob is defined by a number of central factors, the surface area, the mass in relation to other bodies, and its field of influence, which is defined as a relational region through which the point merges or changes due to the influence of other points. There is one possibility when two or more points are near each other:

- They redefine their common surfaces based on the properties of gravity.

- Or, they merge into a unified surface through the interactions between their centers and zones of inflection and fusion $[2,6]$.

As an example, BMW Pavilion in Frankfort, Germany, see Fig 19. designed by Bernard Franken (1999). The Clean Energy driving with hydro and solar energy and the aid of hydrogen is expressed objectively in the form of a drop of water see Fig20

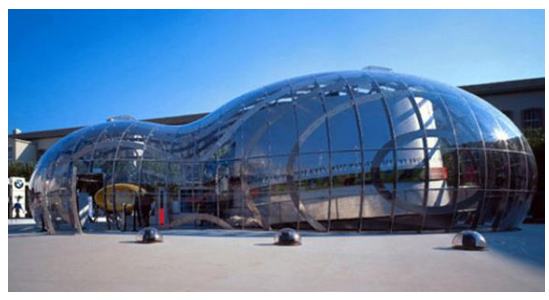

Fig. 7. BMW Pavilion in Frankfort, Germany, by Bernard Franken [6].

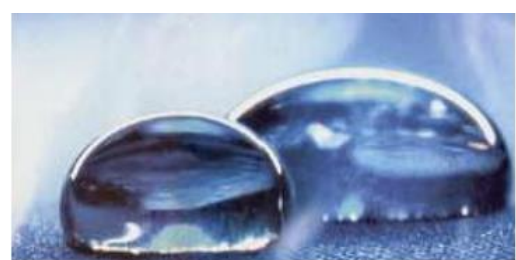

Fig. 8. Design concept inspired by two drops of water [6].

\subsection{Genetic Algorithms}

Genetic algorithms are an artificial intelligence process based on natural selection and evolution[12]. That base mainly on genetic rules similar to the genetic rules in living organisms. It is widely used in the optimization of prior designs or creating new designs from the beginning. It shows a great ability to derive a very large number of alternatives in a very short time, which helps designers in the decisionmaking process $[8,12]$.

Karl Chu, who relies on the computational power of computers to create a "genetic architecture", emphasizing metaphysics in architecture and mathematical operations. So, he began by writing an algebraic equation in which six primary groups were produced from three main preliminary elements and gave each element the letters "A", "B" and "C" and studied the continuous developments in the later generations such as the X-Phylum project see Fig 21 . $[1,13]$.

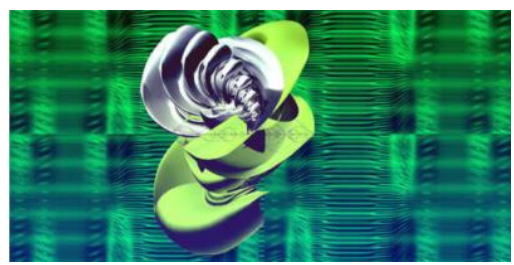

Fig. 21. Various pictures for the XPhylum genetic space [1]. 


\subsection{Performative Architecture}

The architecture that utilizes building performance as the main guide for the design process and adopts many priorities based on performance evaluation, in the design of cities, buildings, landscapes and infrastructure networks $[5,17]$. This approach places the priority on meeting the building's requirements over the concern for its formative composition, as it uses digital techniques (quantitative and qualitative) based on simulating the building performance, thus allowing a new and comprehensive direction for the design of the built environment. Performative design is based on simulations of different performances such as financial, spatial, social, cultural or technical (such as (structural, thermal, acoustic, environmental, ... etc.) $[1,18]$.

As an example, London City Hall see Fig 22. designed by Norman Foster in (1998). Is a distinctive building designed to be environmentally friendly while providing a river view and an integrated energy solution in the building.

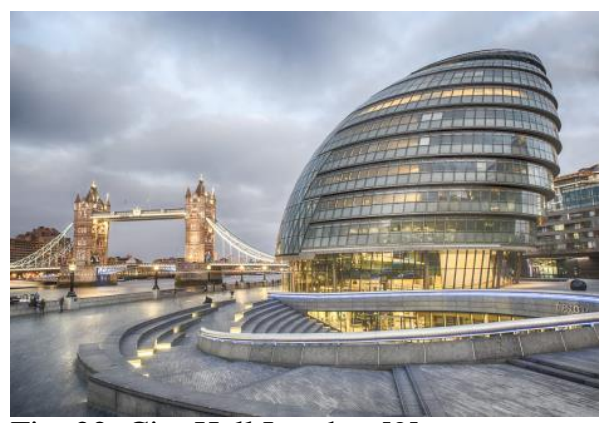

Fig. 22. City Hall London [9].

Architects has adopted a number of stages for this:

- Design started with a sphere with the minimum surface area at a certain volume (the ideal solution from an environmental point of view, as it can absorb the least amount of heat) see Fig 23.

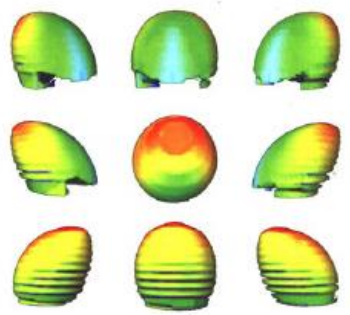

Fig. 23. Solar radiation simulation [9].
- Several modifications have been made, so that the building takes the shape of a cobblestone to meet environmental requirements as:

- Directing the axis of the building with the midday sun, which made the building form have the least surface area facing the sun.

- The side facades are curved, representing the least area in the east and west, facing the lowest angle of the sun. While the building sector appears from the north side, it is mostly round, which provides the maximum field of view overlooking the river

- Modify the building form to meet environmental requirements: Solar energy was studied for the proposed design, and a color coded image was presented that expresses the amount of energy gained by each of the building's external panels during the year. $[3,13]$.

\section{Third classification (Models of Digital Design)}

El-Sayed [6]provides a framework that define taxonomy for digital design models and their associated digital technologies, which helps in understanding the relationship between design concepts and terms such as models, techniques and technology as follows: Formation, Generative and Performance models.

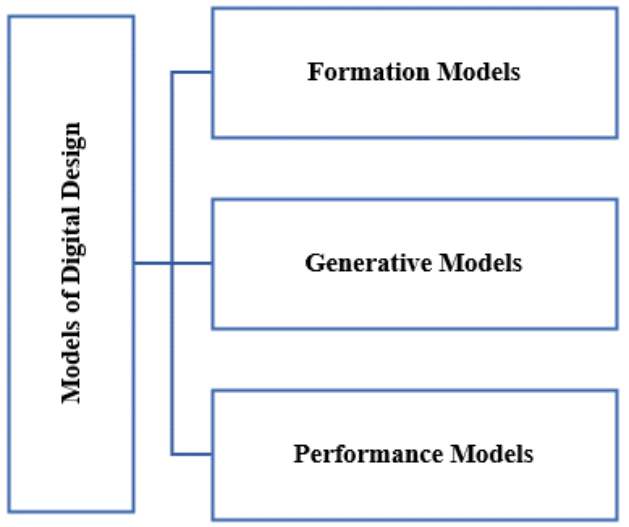

Fig. 24. Digital design models 


\subsection{Formation Models}

Form finding process is considered a type of accelerated motion, as a lot of information is added integrally to the building model. This sequential and integrative addition results in unforeseen and unpredictable effects and is more capable of resonating on different levels than direct ideological expressions, metaphors, allegories, or transcription.

As a result, the traditional ways of expressing the design concept (paper-based) lose their importance and centrality as an intellectual basis for explaining the processes and knowledge associated with digital design, as the digital design theory transformed the concept of the form into the concept of formation. In addition to exploring complex geometries, digital design models have become a means of formulating design concepts, and thus formation constitutes a radical departure away from graphical representations and illustrations. $[4,6]$.

There are two digital technologies related to this design model: animation and parametric design, with topology playing a major role in both. "formation by animation" provides the concept of "dynamic design" while parametric modelling introduced the concept of topological differences [6]. In parametric modelling, the form is expressed through a number of parameters not its shape and by giving different values to these variables, an infinite number of different configurations can be obtained [18].

\subsection{Generative Models}

These models of digital design are characterized by the presence of mathematical mechanisms for generative processes, compared with formal models, the shapes and formations are the result of generative processes developed in advance. One of the most important patterns used in the field of architectural design are Evolutionary models and Shape Grammers $[20,21]$. The $1^{\text {st }}$ approach depends on simulating the rules of natural growth such as the process of reproduction and biotransformation The second provides a computational approach to formulate generative systems for the design process, and the most important type of it is the parametric shape grammar, where form is defined by a number of criteria and parameters that are related to a specific context and shapes. There are many applications of this approach in topological studies of architectural and structural design[6, 19].

\subsection{Performance Models}

Performance models are based on simulation. There are many digital tools used in simulation, analysis and evaluation of the different performances of a building [17, 20,21]. Current digital design techniques refer to a shift from analytical simulation to relying on building performance simulations to infer new architectural forms, and design modification in the initial stages of the design process, instead of analyzing building performance and modifying it to match the results. According to this approach, performance is the ability to directly act on the quantitative characteristics of a particular design in addition to qualitative characteristics such as spatial factors in addition to the technical simulation of structural, acoustic performance, etc. [22].

\section{Comparative analysis between various digital morphogenesis in architecture:}

Digital revolution affected all aspects of life and as a result many schools of thought are based on digital techniques not as representation tools but as generative tools at early stages of the design process. The architect must remain aware of all these recent approaches[18]. Complex, non-uniform structures are increasing recently in architectural discourse due to the wide use of these computational media, fabrication and mass customization. As a result, many unprecedented challenges and difficulties appeared in architectural work. Comparing the various digital morphogenesis in architecture, this paper looks for approaches to architectural designing that can extend architects' creative repertoire [10].

So, it is of key importance to study these different approaches and through a comparative analysis that aims to investigate main features of digital morphogenesis as a source of inspiration and main guide in building form finding using computational media, not only as representational tools but also generative tool and transformation. Understanding these approaches with comparing them, helps to deduce similarities and differences for these fields. In addition to declare their potentials, advantages and scope of application [23]. 
Table 1. Comparative analysis between digital morphogenesis in architecture

\begin{tabular}{|c|c|c|}
\hline Approach & Main Features & Advantages \& potentials \\
\hline $\begin{array}{l}\text { Topology } \\
\text { architecture }\end{array}$ & $\begin{array}{l}\text { - The study of intrinsic, qualitative properties of geometric forms that } \\
\text { are not normally affected by changes in size or shape. } \\
\text { - Differs from the Euclidean geometry of discrete volumes represented } \\
\text { in the Cartesian coordinates of the space. } \\
\text { - By using a geometric shape made up of connected curves and surfaces } \\
\text { known as NURBS curves [10]. } \\
\text { - Surfaces are able to control by changing the location of the control } \\
\text { points, the associated weights and the knots that form them [1]. }\end{array}$ & $\begin{array}{l}\text { It blurred the boundaries between exterior and } \\
\text { interior and procreates potential of structuring, } \\
\text { organizing and forming principles [23]. }\end{array}$ \\
\hline $\begin{array}{l}\text { Parametric } \\
\text { Architecture }\end{array}$ & $\begin{array}{l}\text { - Form finding depends on parameters, as location, structural loads, } \\
\text { solar radiation, cost and wind [14,15]. } \\
\text { - By changing parameters values, we get infinite number of design } \\
\text { solutions. } \\
\text { - Parametric design as utilizing specific tools such as (Grasshopper, } \\
\text { Maya MEL, Rhino Scripting platforms) to improve configuration by } \\
\text { interconnecting and planning design elements [13]. }\end{array}$ & $\begin{array}{l}\text { - Useful for modeling infinitely variable } \\
\text { potentialities of geometries from biological forms. } \\
\text { - Paramorph uses biological parametrics in a digital } \\
\text { media as an intellectual design tool }[15,20] \text {. }\end{array}$ \\
\hline $\begin{array}{l}\text { Animate } \\
\text { Architecture }\end{array}$ & $\begin{array}{l}\text { - Uses animation techniques as generative tools not only for } \\
\text { representational purposes. } \\
\text { - Form follows force and generated within a context of effective and } \\
\text { dynamic flows, rather than a general envelope that is neutral and } \\
\text { impartial of forces and characterized by stability [2]. } \\
\text { - Force acts as an initial condition, changes the atmosphere, which } \\
\text { effects both motion and particular inflections of form }[1,10] \text {. }\end{array}$ & $\begin{array}{l}\text { - Animation tools can affect the creative process of } \\
\text { form generation in computation media. } \\
\text { - Widely used in aeronautical, naval and automobile } \\
\text { design by employing this approach to model form } \\
\text { in a space that is a medium of movement and force } \\
{[8,17] \text {. }}\end{array}$ \\
\hline $\begin{array}{l}\text { Metamorphic } \\
\text { Architecture }\end{array}$ & $\begin{array}{l}\text { - Based on creating a simple form and then making definite } \\
\text { transformations such as bending, twisting, lattice box or morphing, etc. } \\
\text { - according to the design concept [1]. } \\
\text { - By adding a fourth dimension "time" to the transformation process, } \\
\text { animation software provides the ability to express the building and } \\
\text { surrounding space then choose the best frames. } \\
\text { - Dissimilar forms are blended to produce a range of hybrid forms that } \\
\text { combine formal attributes of the base and target objects [23]. }\end{array}$ & $\begin{array}{l}\text { The most suitable approach to generate a hybrid } \\
\text { form resulting from two distinct forms by using } \\
\text { morphing technique between them. } \\
\text { - Digital media offers wide range of transformations } \\
\text { resulted in variety of generated forms [6,17]. }\end{array}$ \\
\hline $\begin{array}{l}\text { Isomorphic } \\
\text { Architecture }\end{array}$ & $\begin{array}{l}\text { - Based on isomorphic polysurface or what is called "meta clay", "meta- } \\
\text { ball" or "blob models". } \\
\text { - Forms are monolithic models with forces of attraction and internal } \\
\text { mass. } \\
\text { - Blob is defined by a number of central factors, the surface area, the } \\
\text { mass in relation to other bodies, and its field of influence. } \\
\text { - through which the point merges or changes due to the influence of } \\
\text { other points }[1,3] \text {. }\end{array}$ & $\begin{array}{l}\text { - Open up another formal paradigm where forms may } \\
\text { undergo variations, giving rise to new possibilities. } \\
\text { - Objects interact together instead of just occupying } \\
\text { space and connected through a system of } \\
\text { interactions where the whole is always open to } \\
\text { variations as new blobs are added or new relations } \\
\text { made, creating new solutions }[10,23] \text {. }\end{array}$ \\
\hline $\begin{array}{l}\text { Genetic } \\
\text { Algorithms }\end{array}$ & $\begin{array}{l}\text { - "Genetic coding" is a source to generative design based on biological } \\
\text { metaphors. } \\
\text { - An artificial intelligence process based on natural selection and } \\
\text { evolution [8]. } \\
\text { - based mainly on genetic rules similar to those in living organisms. } \\
\text { - It is widely used in the optimization of prior designs or creating new } \\
\text { designs from the beginning. } \\
\text { - Resembles natural evolution more closely than most other methods } \\
\text { [2,5]. }\end{array}$ & $\begin{array}{l}\text { - Can be used in architecture as a production of form, } \\
\text { organization of space or development of structural } \\
\text { system. } \\
\text { - Based on resolving challenges that have already } \\
\text { been resolved by nature as a source of inspiration } \\
\text { [4]. }\end{array}$ \\
\hline $\begin{array}{l}\text { Performative } \\
\text { Architecture }\end{array}$ & $\begin{array}{l}\text { - Building performance is the main guide for the design process, of } \\
\text { cities, buildings, landscape and infrastructure networks. } \\
\text { - Based on simulations of different performances such as financial, } \\
\text { spatial, social, cultural, structural, acoustic or environmental. } \\
\text { - The final optimized solution may not be acceptable aesthetically, so } \\
\text { the designer selects sub-optimal whose appearance would be } \\
\text { acceptable [7,14]. }\end{array}$ & $\begin{array}{l}\text { - Adding analysis and optimization tools to the initial } \\
\text { stage of the design process, resulted in forms with } \\
\text { improved performances [10]. } \\
\text { - Forms will not become merely an expression of } \\
\text { aesthetic considerations, but rather become a good } \\
\text { expression of new architectural movements } \\
\text { fulfilling sustainability and building needs [1,15]. }\end{array}$ \\
\hline
\end{tabular}


Comparing these approaches, it could be detected that they have many features in common, such as consistent, continual and dynamic transformations and the ability to produce complex geometries through digital media. They provide new ways to generate infinite number of solutions in architectural form finding. They make an emphasis shift from the concept of "form making" to the "form finding".

Moreover, most approaches focus only on the qualitative and aesthetic aspects of the architectural form and didn't take into consider building performances such as functional, environmental, structural or acoustic except performance- oriented design makes priority to the performative aspects, which resulted in a un-optimal solution at one hand and an optimal solution at the other hand, which may not be acceptable from aesthetic point of view. In this case the designer selects sub-optimal solution that could be aesthetically accepted.

Many considerations should be taken into account, the relationship between functional requirements and building form, aesthetic considerations and construction systems, the impact of the surrounding environment and structure, user needs and construction cost. In order to achieve balance between these different qualitative and quantitative aspects, an integrated design: generative performative design approach is proposed in which moves away from architecture based on purely aesthetic and appearance concerns towards an architecture justified by its performance.

\section{7. conclusion}

The followings have been concluded:

- Some architectural schools encourage that form finding is based on the personal inspiration, intuition of the architect and his sense of beauty.

- Many form finding philosophies varies even the form could be derived from nature, the context, geometry or performance.

- Computationally generated forms (digital morphogenesis) could be categorized as: topology, parametric, animate, metamorphic, isomorphic, genetic algorithms and performative architecture.

- Through investigating these approaches, it could be found that, some of them focus only on the qualitative and aesthetic aspects of the architectural form and didn't take into consider building performances such as functional, environmental, structural or acoustic, while others focus on the performative aspects, fulfilling all building requirements, construction cost and user needs.

- Due to Latest developments, in addition to dealing with complex geometries, form finding should depend on an integrated design: generative performative design approach approach, that achieves balance and takes into consider both aesthetic aspects as well as the performative considerations of the building such as functional, environmental, structural or economic, in order to find the optimal solution at early stages of the form finding process.

\section{References}

[1] B. kolarevic, Ed., "Architecture in the Digital Age Design and Manufacturing", New York, Spon Press, pp. 17-46, 2003.

[2] M. El-Iraqi, "form generation in Architecture -using tools based on evolutionary and mathematical functions", MSC, Department of Architecture, Ain Shams University, Faculty of Engineering, pp. 65, 2008.

[3] E. Fasoulaki, "Integrated Design-A Generative MultiPerformative Design Approach", MSC, Department of Architecture, University of Patras, Massachusetts Institute of Technology, pp. 13-16, 2008.

[4] K. Terzidis, "Expressive Form-A conceptual approach to computational design", New York,Spon Press, pp. 13, 2003.

[5] C. M. Cardoso, "Performance-Based Design: From Form Making to Form Finding", Architecture department, Tecnico Lisboa, pp. 23-24, 2017.

[6] S. E. El-Sayed, "The Effect of Digital Technology on Form Generation of Building Architecture", Architecture department, Cairo university, pp. 78-81, 2010.

[7] R. Oxman and R. Oxman, "Theories of the Digital in Architecture", London, Routledge, pp. 20, 2013.

[8] N. Lotfi, "Nature-Inspired Design Processes: The Adaption of various Principles of Biology as the base for a Holistic Approach towards a New Strategy within the Design Process", Faculty of Postgraduate Studies and Scientific Research, German university in cairo, pp.23, 2014.

[9] M. Turrin, P. von Buelow, and R. Stouffs, "Design explorations of performance driven geometry in architectural design using parametric modeling and genetic algorithms", Advanced Engineering Informatics, vol. 25, N.4 pp. 656-675, 2011.

[10] A. Agkathidis, "Generative Design: Form-Finding Techniques in Architecture", London Laurence King Publishing, pp. 8-15, 2015.

[11] K. Jormakka, Basics Design Methods. Basel: Birkhäuser, PP.9-11, 2013.

[12] M. Hensel, A. Menges, and M. Weinstock, Eds., "Techniques and Technologies in Morphogenetic 
Design", Great Britain,Wiley-Academy, Vol.76, No.2 pp. 12, 2006.

[13] H. M. T. E. Daly, "Architecture in the Age of Information Technology", M.Sc, Departement of Architecture, Ain Shams University, pp. 70-127, 2004.

[14] W. Suyoto, A. Indraprastha, and H. W. Purbo, "Parametric Approach as a Tool for Decision-making in Planning and Design Process - Case study: Office Tower in Kebayoran Lama", Journal of Procedia Social and Behavioral Sciences, Vol. 184, N. 5 PP. 328 $-337,2015$.

[15] D. J. Gerber, "Parametric Practices: Models for Design Exploration in Architecture", PHD, Graduate School of Design, Harvard University, pp. 32-40, 2007.

[16] R. Woodbury, O. Y. c. Gun, B. Peters, and M. Sheikholeslami, "Elements of Parametric Design", Abingdon, USA , Canada, Routledge, pp. 180-185, 2010.

[17] M. U. Hensel, "Performance-oriented ArchitectureTowards a Biological Paradigm for Architectural Design and the Built Environment", vol. 3, pp. 1-2, 2010.

[18] Y. J. Grobman and a. E. Neuman, Eds., "performalism: fom and performance in digital architecture", Routledge, pp. 10-11, 2012.

[19] Eltaweel and Y. SU, "Parametric Design and Daylighting: A Literature Review", department of architecture and built environment, university of Nottingham, UK, pp. 2-3, 2017.

[20] E. A. Caetano, "Computational design in architecture: Defining parametric, genertive, and algorithmic design", Journal of Frontiers of Architectural Research, Vol. 9, N. 2 PP. 237 - 300, 2019.

[21] B. Kolarevic and A. Malkawi, Eds., "Performative Architecture-Beyond Instrumentality", New York, Spon Press, pp. 30, 2005.

[22] R. Oxman, "performance-based design: current practices and research issues", International Journal of Architectural Computing, Vol. 2, N. 1 PP. 4-5 , 2008.

[23] S. Roudavski, "Towards Morphogenesis in Architecture", International Journal of Architectural Computing, Vol. 7, N.3 pp. 345-374, 2009. 